DOCUMENTO

\title{
Carta encaminhada ao Presidente da Câmara de Educação Básica do Conselho Nacional de Educação
}

\begin{abstract}
Brasília, 1 de junho de 2011.
\end{abstract}
Excelentíssimo Senhor Presidente da Câmara de Educação Básica do CNE Francisco Aparecido Cordão

O presidente do Conselho Nacional das Instituições da Rede Federal de Educação Profissional, Científica e Tecnológica (CONIF) Magnífico Reitor do Instituto Federal do Ceará senhor Claudio Ricardo Gomes de Lima, Pró-Reitores de Ensino da Rede Federal de EPT e educadores dos campos Trabalho e Educação e Educação de Jovens e Adultos da Associação Nacional de Pós-Graduação Pesquisa em Educação (ANPEd), presentes à reunião realizada na SETEC no dia 23/05/2011, convocada com a finalidade de discutir o posicionamento dessa Secretaria sobre o parecer e Resolução das Diretrizes Curriculares Nacionais para a Educação Profissional Técnica de Nível Médio em pauta no Conselho Nacional de Educação, manifesta discordância em relação ao texto apresentado sobre a matéria, por compreender que ele expressa uma concepção restrita de educação profissional e de sua relação com o ensino médio.

$\checkmark$ Diverge dos pressupostos e objetivos das Diretrizes Curriculares Nacionais para o Ensino Médio, aprovadas recentemente, pelo CNE.

$\checkmark$ Fortalece a separação entre o ensino médio e a educação profissional estabelecida pelo decreto 2.208/97 já revogado.

$\checkmark$ Não incorpora os pressupostos filosóficos e educacionais que sustentam a formação integrada prevista pelo decreto n. 5.154/04.

$\checkmark$ Enfatiza a centralidade da educação profissional na dimensão econômica, tomando o mercado como instrumento regulador da sociabilidade humana.

$\checkmark$ Baseia-se no currículo centrado na pedagogia das competências.

$\checkmark$ Aponta para uma organização curricular fragmentada, caracterizada pelas saídas intermediárias, implicando a precarização da formação.

Diante disso, reiteramos o documento elaborado no âmbito do GT constituído pela SETEC, em 2010 (Educação Profissional Técnica de Nivel Médio em 
Debate), o qual expressa os conceitos e concepções que vêm sendo assumidos pelo MEC, desde 2003, em relação à educação profissional:

$\checkmark$ Centralidade no ser humano e suas relações sociais, sem ignorar as exigências da produção econômica, como campo de onde os sujeitos sociais retiram os meios de vida.

$\checkmark$ Formação que aponta para a superação da dualidade histórica entre formação básica e formação profissional.

$\checkmark$ Currículo centrado na concepção de formação humana integral, tendo como eixo estruturante a integração entre trabalho, ciência, tecnologia e cultura, baseando-se no trabalho como princípio educativo e, dentre outros, nos seguintes fundamentos pedagógicos:

$\checkmark$ Construção coletiva do Projeto Político-Pedagógico;

$\checkmark$ Pesquisa como princípio pedagógico;

$\checkmark$ Articulação com o desenvolvimento socioeconômico e a educação ambiental.

Nesse sentido, consideramos a impossibilidade de propor emendas ao documento em trâmite e sugerimos que seja reiterado ao CNE o documento apresentado por esse ministério, por meio da SETEC em agosto de 2010: Educação Profissional Técnica de Nivel Médio em Debate.

Para melhor compreensão dos argumentos elencados, apresentamos a seguir uma síntese histórica do processo de produção do documento mencionado:

No decorrer de 2010, iniciaram-se dois movimentos no CNE com implicações diretas para a educação de adolescentes, jovens e adultos do país: a elaboração de diretrizes para o ensino médio e a elaboração de diretrizes para a educação profissional técnica de nível médio. Em ambos os casos foram produzidos documentos de contribuição/contraponto. $\mathrm{O}$ debate iniciou-se com uma proposta de parecer do Senhor Conselheiro Francisco Aparecido Cordão sobre as diretrizes para e educação profissional técnica de nível médio. Esse parecer e a correspondente proposta de Resolução retomam todos os fundamentos vigentes nos anos 1990, fundamentando as diretrizes na noção de competências para a laborabilidade e para a empregabilidade. A partir da divulgação da nova proposta de regulação da educação profissional técnica de nível médio, houve uma mobilização do Fórum de Dirigentes de Ensino (FDE) da rede federal de EPT e da ANPEd.

Considerando a complexidade, a importância e a premência da matéria, o Conselho dos Dirigentes das Instituições Federais de Educação Profissional, Científica e Tecnológica (CONIF), por intermédio do FDE, juntamente com a Secretaria de Educação Profissional e Tecnológica do Ministério da Educação (SETEC/MEC) promoveram, em Brasília, nos dias 5 e 6 de maio, o Seminário da Educação Profissional e Tecnológica. Participaram desse encontro, além dos 
dirigentes de ensino das instituições federais, pesquisadores da área, conselheiros e assessores do CNE. A Carta do Seminário estabeleceu entre os encaminhamentos a ampliação do debate com a participação das demais redes públicas de ensino e a criação de grupo de trabalho com a colaboração de pesquisadores da área.

Em consequência, a SETEC/MEC reuniu um Grupo de Trabalho (GT) para o qual foram convidadas quatro Secretarias do MEC - Secretaria de Educação Básica (SEB), Secretaria de Educação (SEESP), Secretaria de Educação a Distância (SEED), Secretaria de Educação Continuada, Alfabetização e Diversidade (SECAD) -, o Ministério do Trabalho e Emprego (MTE); o Ministério da Saúde (MS), representado pela Escola Politécnica de Saúde Joaquim Venâncio (EPSJV - FIOCRUZ); os gestores estaduais de educação profissional, vinculados ao Conselho Nacional dos Secretários de Educação (CONSED); o Fórum dos Conselhos Estaduais de Educação; o Conselho Nacional das Instituições da Rede Federal de Educação Profissional, Científica e Tecnológica (CONIF); a Central Única dos Trabalhadores (CUT), representada pela Escola dos Trabalhadores; o Sindicato Nacional dos Servidores Federais da Educação Básica, Profissional e Tecnológica (SINASEFE); e a Associação Nacional de Pós-Graduação e Pesquisa em Educação (ANPEd - GT Trabalho e Educação e GT Educação de Jovens e Adultos), contando com a colaboração de renomados pesquisadores da educação profissional e tecnológica. O GT reuniu-se durante os meses de junho e julho, em três encontros presenciais em Brasília, recebendo ainda diversas contribuições enviadas espontaneamente por outros órgãos, instituições de ensino e pesquisadores.

O documento produzido por este GT (Educação Profissional Técnica de Nivel Médio em Debate) retoma e sintetiza as discussões e produções acerca do ensino médio integrado, da politecnia e da formação humana integral que vêm sendo construída nas últimas décadas.

Posteriormente, iniciou-se o movimento relativo às diretrizes para o ensino médio. Novamente integrantes do mesmo grupo, durante a 33a Reunião da ANPEd, em Caxambu, MG, juntamente com a Secretária de Educação Básica do MEC, mobilizaram-se e produziram um novo documento (Diretrizes Curriculares Nacionais para o Ensino Médio. Proposta de Debate ao Parecer), cujo conteúdo é convergente com o primeiro documento (Diretrizes para a EP Técnica de Nivel Médio). Durante sua elaboração fez-se a aproximação das duas discussões (diretrizes para o EM e para a EP), com a expectativa de que, no âmbito do CNE, fosse produzido um único parecer e duas resoluções específicas (uma para o ensino médio e outra para a educação profissional técnica de nível médio).

Não obstante, esse caminho não foi viabilizado por dificuldades de entendimento político no âmbito da Câmara de Educação Básica/CNE, que não concordou com a discussão conjunta dos documentos. O conselheiro José Fernandes de Lima foi designado relator das diretrizes do ensino médio e o grupo mencionado anteriormente lhe enviou o documento produzido em relação ao ensino médio. $\mathrm{O}$ 
parecer do conselheiro incorporou grande parte dos fundamentos do documento que lhe fora encaminhado. Esse parecer foi aprovado no CNE no dia 4/05/2011.

Quanto às diretrizes para a educação profissional técnica de nível médio, o CNE emitiu, já em 2011, uma nova proposta de parecer e de resolução que apesar de incorporar alguns trechos do documento produzido pelo GT, já referenciado, mantém explicitamente a perspectiva do currículo centrado em competências para empregabilidade.

Dessa forma, têm-se as diretrizes para o ensino médio que sinalizam para a possibilidade de se avançar na perspectiva da politecnia e da formação humana integral, enquanto as diretrizes para a educação profissional técnica de nível médio apontam para uma direção oposta - competências para mercado. Além disso, faz uso de citações de textos legais de forma inadequada.

Diante do exposto, solicitamos ao Senhor Francisco Aparecido Cordão, presidente da Câmara de Educação Básica do CNE:

1| retirar da pauta do $\mathrm{CNE}$ a proposta de parecer e de resolução em trâmite por ser contraditória com as Diretrizes Curriculares Nacionais para o ensino médio e com os documentos produzidos pelo MEC desde 2003;

$2 \mid$ atuar nesse processo visando garantir a coerência e unicidade entre as diretrizes da educação profissional técnica de nível médio, a serem votadas, e as diretrizes do ensino médio, já aprovadas;

3| reafirmar o documento Educação Profissional Técnica de Nível Médio em Debate.

Assinam o documento um grupo ampliado de 35 educadores, reunidos na SETEC/MEC, em Brasília, em 23 de maio de 2011, representantes das seguintes instituições: IFS, IFMG, IFAc, IFRGS, IFCe, FIOCRUZ, FEEVALE, IFSC/ CONIF, Colégio Pedro II, IFF, IFCe/FDE, IFRJ, UFF, UFRGS, UFTPr, UFG, UFSM, IFRN, SEE-RS, IFG, IFES, IFA1, SECAD, SEB, IFB, SETEC/MEC, UERJ.

(O documento teve por base a Carta de Natal, assinada por Dante Henrique Moura/IFRN, Domingos Leite Filho/UFTPr, Lucília Regina Machado/UNA, Maria Ciavatta/UFF, Maria Margarida Machado/UFG, Marise Ramos/UERJ e EPSJV-FIOCRUZ, Nilva Schroeder/IFSC e CONIF, aprovada durante o Colóquio "A Produção do Conhecimento em Educação Profissional”, realizado no IFRN, Natal, RN, em 19 e 20 de maio de 2011). 